\title{
A Novel Approach for English Phonetic Alphabet in Wireless Communication
}

\author{
Yuhui Wan \\ The High School Affiliated to Nanjing Normal University, Nanjing, China \\ Email: 442352742@qq.com
}

Received May 22, 2013; revised June 25, 2013; accepted July 24, 2013

Copyright (C) 2013 Yuhui Wan. This is an open access article distributed under the Creative Commons Attribution License, which permits unrestricted use, distribution, and reproduction in any medium, provided the original work is properly cited.

\begin{abstract}
In this paper a novel approach of English Phonetic Alphabet applicable to Chinese people was introduced. This novel English Phonetic Alphabet was specially designed in line with the characteristics of radio telephone frequency communication in China and pronunciation habit and English level of most of Chinese people; which not only can improve the voice quality and guarantee accurate transfer of information, but also is integrated with the pronunciation characteristics of Chinese language, with the functions to avoid the uncommon, easily confusing and difficultly pronouncing English words, and efficiently improve the wireless communication efficiency.
\end{abstract}

Keywords: Radio Telephone Frequency Communication; English Phonetic Alphabet

\section{Introduction}

Radio telephone frequency communication system (hereinafter referred to as the "RTFCS") is a voice frequency communication system adopting VHF or UHF handheld radio station as a single communication unit, vehicle-mounted radio station as the team communication unit, and VHF or UHF radio relay station as the communication platform [1]. RTFCS is a complete set of wireless equipment system allowing to use in the mobile condition and realize point-to-point or point-to-multipoint communication; where a unit sends information at the same time, and multiple units can realize information exchange and interaction concurrently and many people can receive the information sent by one same unit concurrently [2].

In recent years, the productivity level of China has been improved too much. As the economy and scientific technology of China advance continuously, the wireless communication system grows out of nothing and keeps improving; and in this process a diversified efficient wireless communication system dominated by radio telephone frequency communication and aided by digital network communication has come into being [3]. Currently the radio telephone frequency communication system popular in China is featured in instant communication, mass response, economy and durability, low operation cost and convenient use. The modern communication equipment, after its emergence, reduces the dependence of people on radio telephone frequency communication, but the role of radio telephone frequency communication system can not be replaced by other means of communication, whichever it is in the daily management or the emergency disposal for emergency [4].

Radio telephone frequency communication system can not be applied without the English Phonetic Alphabet. In a radio telephone frequency communication, the English Phonetic Alphabet popular in the world has been widely used. The "Standard Phonetic Alphabet of International Telecommunication Union" has excellent functions of improving voice quality and guaranteeing smooth information transfer, but it is hard to fit with the pronunciation habit and English level of most of Chinese, therefore it is not convenient to use and master for the people who use Chinese as the mother tongue. Most of Chinese do not know any English words among them, and some English words can not be accurately identified since their uncommonness, even some other words can not be pronounced easily or accurately, so it is very difficult for them to remember; certainly these English words are prone to be pronounced or heard wrongly; in this case, the radio communication efficiency will be reduced, the information can not be transferred accurately and quickly, even the working efficiency and working enthusiasm of managerial staff for using wireless communication equipments will be affected hugely.

So how should we improve the reliability of radio tele- 
phone frequency communication system? Nowadays, the method to improve the reliability of radio telephone frequency communication system depends on the update and upgrade of hardware, such as using more advanced communication equipment, adding relay stations etc., which are workable sometimes, but need huge cost and practitioners need to become familiar with them over a period of time [5]. From the prospective of the author of the paper, the mostly economical and efficient method comes from the English Phonetic Alphabet.

Through researches, it is found that the pronunciation habit and characteristics of Chinese are different from that of Europeans and Americans. For instance, there is no uvular or lingual pronunciation in Chinese, and the musical scale continuity of Chinese is very weak; furthermore as for the English level and vocabulary, most of Chinese living in China know only the everyday vocabulary; therefore it is very urgent to design a "simple and concise English Phonetic Alphabet" with the features of Chinese pronunciation for Chinese. Such English Phonetic Alphabet can avoid uncommon, easily confusing and difficultly pronouncing English words, comply with the linguistic pronunciation habit of Chinese, allow to use quickly, overcome the difficulty and problem related to the use of English letters in radio communication, improve the original voice quality, guarantee smooth and accurate information transfer and improve radio communication efficiency.

\section{Status Quo and Problems of Existing Digit and English Phonetic Alphabet}

Digit or English Phonetic Alphabet is widely used in the amateur radio telephone frequency communication so as to solve the problem in the radio communication, namely the voice can not be heard clearly or identified since the different accent, similar pronunciation, or the ionized stratum declines [6]. ICAO (International Civil Aviation Organization) adopts the similar phonetic alphabet for the communication words, and the amateur radio stations adopt the same phonetic alphabet when involving in call sign, name or QTH (site of radio station), even for the voice that is prone to be heard wrongly, such as S and X, $\mathrm{B}$ and $\mathrm{P}, \mathrm{D}$ and $\mathrm{T}, \mathrm{G}$ and $\mathrm{J}, \mathrm{M}$ and $\mathrm{N}, \mathrm{R}$ and $\mathrm{I}$.

\subsection{Chinese Digital Interpretation Method}

In the radio communication, the call sign, name, address and other information of calling party and called party can not be done without digit and English letter. The radio telephone frequency communication system in the early time in China was mainly used for traffic control. At that time, since vehicle's registered plate number contained only one English letter and six digits, the Chinese digital interpretation method was popularized (see
Table 1). The Chinese digital interpretation method mainly focuses on interpreting digit, to eliminate or relieve the problem that digital information can not be transferred accurately resulting from much noise or voice distortion in radio communication. The design principle of such digital interpretation method is very helpful for the author of the paper to design the novel English Phonetic Alphabet.

However as the economy develops and the living level of people improves continuously, vehicle increases day after day, and English letter appears in the last six numbers of the vehicle's registered plate; moreover the percentage of English letter increases continuously, especially the vehicle's registered plate number becomes more complicated after vehicle administration offices of many places adopt the registered plate number self-selection method, where the original method to guarantee the voice quality of radio telephone frequency communication only through Chinese digital interpretative method can not meet the communication demands of current traffic management work [7]. The emergence of the increasing English letters makes the originally simple Chinese digital interpretative method hard to guarantee the voice quality of telephone frequency communication. When such situation emergences in other fields, it is imperative to adopt and popularize the English Phonetic Alphabet in radio telephone frequency communication system.

\subsection{English Phonetic Alphabet}

As for radio communication technicians, English Phonetic Alphabet is the basic knowledge. In the amateur radio, especially in the short-wave single side band and in the FM mode communication, the English Phonetic Alphabet is widely popularized. HAM should also learn the English Phonetic Alphabet firstly. Once the English Phonetic Alphabet is mastered well, the voice communication can be heard smoothly.

The English Phonetic Alphabet of ICAO is very popular for amateur communication at abroad. Among them, most letters are shown by common words, for instance the name of country, place or person usually shows the first letter of each word. As for the person who uses the

Table 1. Pronunciation of Chinese digital interpretation method.

\begin{tabular}{cccc}
\hline Digit & Chinese Pinyin & Digit & Chinese Pinyin \\
\hline 0 & Dong & 5 & Wu \\
1 & Yao & 6 & Liu \\
2 & Liang & 7 & Guai \\
3 & san & 8 & ba \\
4 & si & 9 & gou \\
\hline
\end{tabular}


English as the mother tongue, it is easy to get the corresponding letter from the word [8]. According to the regulations of ITU (International Telecommunications Union), all amateur communications should adopt the phonetic alphabet of ICAO as the standard alphabet. Besides, the names of some places, persons and countries well known by people in the world are used for interpreting 26 English letters, in this case the standard English letter analysis method is formed (see Table 2). For instance, A pronounces "Alpha", C pronounces "Charlie", R pronounces "Romeo", J pronounces "Juliet" etc., the problem, namely the difficult writing or inaccurate hearing caused by different accent or similar pronunciation (such as " $\mathrm{S}$ " and

Table 2. Standard English Phonetic Alphabet.

\begin{tabular}{|c|c|c|}
\hline Letter & $\begin{array}{c}\text { Standard } \\
\text { interpretation }\end{array}$ & $\begin{array}{c}\text { Interpretation } \\
\text { by name of place }\end{array}$ \\
\hline A & AlPHA, ALFA & AMERICA \\
\hline B & BRAVO & BOSTON \\
\hline $\mathrm{C}$ & CHARLIE & CANADA \\
\hline $\mathrm{D}$ & DELTA & DENMARK \\
\hline $\mathrm{E}$ & $\mathrm{ECHO}$ & ENGLAND \\
\hline $\mathrm{F}$ & FOXTROT & FLORIDA \\
\hline G & GOLF & GERMANY \\
\hline $\mathrm{H}$ & HOTEL & HONOLULU \\
\hline I & INDIA & ITALY \\
\hline $\mathrm{J}$ & JULIET & JAPAN \\
\hline K & KILO & \\
\hline $\mathrm{L}$ & LIMA & LONDON \\
\hline M & MIKE & MEXICO \\
\hline $\mathrm{N}$ & NOVEMBER & NORWAY \\
\hline $\mathrm{O}$ & OSCAR & ONTARIO \\
\hline $\mathrm{P}$ & PAPA & PETER \\
\hline Q & QUEEN & QUEBEC \\
\hline $\mathrm{R}$ & ROMEO & \\
\hline $\mathrm{S}$ & SIERRA & \\
\hline $\mathrm{T}$ & TANGO & TOKYO \\
\hline U & UNIFORM & UNITED \\
\hline V & VICTOR & VIRGINIA \\
\hline W & WHISKEY & WASHINGTON \\
\hline $\mathrm{X}$ & X-RAY & \\
\hline $\mathrm{Y}$ & YANKEE & YOKOHAMA \\
\hline Z & ZULO & ZANZIBAR \\
\hline
\end{tabular}

"X") can be solved in the daily communication.

Besides, the Soviet Union proposed an "English Phonetic Alphabet of the Warsaw Treaty Organization"; since the English letters were mostly shown by Russian, it is not practical to Chinese; therefore it is not described any more herein.

In China, when making radio communication, provided that there is communication interference and insufficient signal strength, it will be difficult to receive; therefore it is necessary to interpret some important characters or words so as to enable the called party to write down accurately. The method to interpret Chinese characters is well known by all of us, so an interpretative method must also be available when pronouncing some English word groups so as to write down easily. In the past, Chinese were used to saying " $A$ " of "A-B-C", "B" of "A-B-C", "C" of "A-B-C" etc. However, we can not interpret all by reading letter according to its sequence; furthermore some letters among the 26 English letters can not be interpreted in this way, and to use the method is not easy to interpret them or is easy to get confusion when interpreting them [9].

Through the research on the amateur radio telephone communication and upon the understanding on the communication system of Europe and America, the author found that there is no English Phonetic Alphabet with the local features available in China, but only a few of HAM and pilots master the English Phonetic Alphabet of ICAO, ITU or the Warsaw Treaty Organization. The reason is that these English Phonetic Alphabets have high requirements on English and Russian level, and ordinary people can not master them easily. Therefore it is very necessary to select rational English words to interpret letters and design an English Phonetic Alphabet suitable for Chinese in accordance with the characteristics of radio telephone frequency communication in China and pronunciation habit and English level of most of Chinese people.

\section{A Novel English Phonetic Alphabet}

Through tests and researches, the author found the "Standard English Phonetic Alphabet" is very difficult to Chinese people, for instance some words are not known (SIERRA, WHISKEY and name of most of places), some words are not pronounced easily or accurately (JULIET and QUEBEC etc.), the "Standard English Phonetic Alphabet", for those only with the vocabulary of senior high school and without mastering the English pronunciation standard, it is very difficult to keep them in mind, realize standard pronunciation and use them fluently. Therefore, in the author's opinion, one of the methods to improve radio telephone frequency communication quality is to popularize the new "English Phonetic Alphabet" in radio communication.

The following new English Phonetic Alphabet is de- 
signed by the author of the paper in accordance with the actual needs of radio communication in China, pronunciation habit and characteristics of most of Chinese people, and the English level of Chinese people, which not only has the Chinese features, but also suits for most of Chinese people for use (this is the experimental version only) (see Table 3 as follows).

During the process of designing "Novel English Phonetic Alphabet", the author considered using Chinese cha-

Table 3. Novel English Phonetic Alphabet.

\begin{tabular}{|c|c|c|c|c|}
\hline \multirow[b]{2}{*}{ Letter } & \multirow[b]{2}{*}{$\begin{array}{l}\text { Interpretation } \\
\text { pronunciation }\end{array}$} & \multicolumn{3}{|c|}{ Selection basis } \\
\hline & & $\begin{array}{l}\text { Standard use } \\
\text { maintained }\end{array}$ & $\begin{array}{l}\text { Use frequency } \\
\text { sequence number }\end{array}$ & $\begin{array}{l}\text { Chinese } \\
\text { common } \\
\text { language }\end{array}$ \\
\hline A & $a-A L F A$ & $\triangle$ & & \\
\hline B & BOY & & 263 & \\
\hline C & CHINA & & & $\triangle$ \\
\hline D & DOG & & 722 & \\
\hline $\mathbf{E}$ & EVEN & & 79 & \\
\hline $\mathbf{F}$ & FATHER & & 463 & \\
\hline G & GIRL & & 285 & \\
\hline $\mathbf{H}$ & HOTEL & $\triangle$ & & \\
\hline I & IF & & 41 & \\
\hline $\mathbf{J}$ & JUST & & 100 & \\
\hline $\mathbf{K}$ & KEEP & & 189 & \\
\hline $\mathbf{L}$ & LILI & & & $\triangle$ \\
\hline M & MOM & & & $\triangle$ \\
\hline $\mathbf{N}$ & NEED & & 127 & \\
\hline $\mathbf{O}$ & OFFICE & & 377 & \\
\hline $\mathbf{P}$ & PACK & & 625 & \\
\hline $\mathbf{Q}$ & QUEEN & $\triangle$ & & \\
\hline $\mathbf{R}$ & RUSSIA & & & $\triangle$ \\
\hline S & STORY & & 523 & \\
\hline $\mathbf{T}$ & TANGO & $\triangle$ & & \\
\hline $\mathbf{U}$ & UNIT & & 214 & \\
\hline $\mathbf{V}$ & VICTOR & $\triangle$ & & \\
\hline W & WIFI & & & $\triangle$ \\
\hline $\mathbf{X}$ & X-RAY & $\triangle$ & & \\
\hline $\mathbf{Y}$ & YET & & 260 & \\
\hline $\mathbf{Z}$ & ZOO & & & $\triangle$ \\
\hline
\end{tabular}

Table: "Use frequency number" in the table above comes from "Use Frequency List of Common Words in English of Senior Middle School" [10]. racter to interpret English letter, however the test shows there is huge difference between Chinese and English pronunciations, and it is very difficult to combine them with each other. In the radio communication dialogue in China, Chinese rather than English is used directly, there is no possibility to have the confusion between English words used for interpreting letter and Chinese dialogue; therefore it is alternative to use the comparatively simple and common English words to interpret letter. In view of the reasons above, the author finally decided to interpret English letter by combining the use of the comparatively simple English words and some proper nouns.

In Table 3, the English words for the new English Phonetic Alphabet are selected by following the principle as follows:

1) The word selected must be the one with the original letter as the initial letter;

2) The word selected must have short syllable and clear pronunciation;

3) The word that is usable in the original standard English Phonetic Alphabet is maintained, such as ALFA, HOTEL, QUEEN and others;

4) The common words with the use frequency ranking top 800 are selected, for instance the use frequency of IF ranks top 41, EVEN ranks top 79 and JUST ranks top 100 [11].

5) The proper nouns well known, easily acceptable and mastered by Chinese people are selected, such as CHINA, LILI, WIFI.

\section{Conclusion}

The "New English Phonetic Alphabet" not only has the functions of "Standard English Phonetic Alphabet of ITU", namely the functions of improving voice quality and guaranteeing smooth information transfer, but also is integrated with the pronunciation characteristics of Chinese language and the English level of Chinese people, where common, easily confusing or difficultly pronouncing English words are avoided. All words to be selected have simple pronunciation, are easy to be pronounced and pronounced clearly, and are easy to be learned. In the normal condition, these words can be preliminarily mastered within one week and can be transferred free between the interpretative pronunciation and English letters after becoming familiar within months. Currently the English Phonetic Alphabet is still under test and plenty of data and comments are needed to acquire and solicit so as to make improvement.

\section{REFERENCES}

[1] X. Xu and Z. G. Zhao, "Security Solutions of Mobile Information System for Police," Technology Square, No. 3, 2010, p. 62 .

[2] R. Xu and S. Y. Zheng,"Comparison and Selection of 
Data Transmission Mode in VHF/UHF Monitoring Station," China Radio, No. 3, 2009, pp. 60-62.

[3] Y. Zhang, F. Xing and C. J. Lu, "Development and Prospect of Wireless Communication Technology," Silicon Valley, No. 23, 2010, p. 18.

[4] M. Li, L. Zhang and G. W. He, "Analysis and Comparison of Wired and Wireless Communication," Computer CD Software and Applications, No. 5, 2012, pp. 25-26.

[5] L. Q. Guo, "Analysis of Aeronautical Radio Interference," China New Technologies and Products, No. 17, 2011, p. 50.

[6] H. Zhao, "On Translation of Phonetic Alphabet," Journal of Hubei Automotive Industries Institute, No. 1, 2000, p. 84.

[7] C. M. Liu, "Discussion on How to Strengthen the Emer- gency Communication Guarantee Capacity of Fire Forces," Science and Technology Innovation Herald, No. 34, 2009, p. 224.

[8] H. Zhao, "Translation for English Phonetic Alphabet," Journal of Hubei Automotive Industrial Institute, No. 1, 2000, pp. 83-85.

[9] R. Mei, "Application of Verbal Communication Encryption in Public Security Work," Journal of Hubei University of Police, No. 6, 2012, pp. 135-136.

[10] http://baike.baidu.com/view/1942073.htm

[11] http://wenku.baidu.com/view/c7109dde6flaff00bed51e0d .html 